\title{
ARQUITETURA HOSPITALAR SUSTENTÁVEL: O CASO DO HOSPITAL ALEMÃO OSWALDO CRUZ
}

\section{SUSTAINABLE HOSPITAL ARCHITECTURE: THE CASE OF GERMAN HOSPITAL OSWALDO CRUZ}

Regina Márcia Gomes de Oliveira ${ }^{1}$ Fernando Guillermo Vázquez Ramos ${ }^{2}$

Resumo: Diante do cenário contemporâneo, que procura ter um olhar cuidadoso para com o meio ambiente, a arquitetura paulistana poderia pensar em mudanças que contribuam com as metas estabelecidas pelo Acordo de Paris (alterações climáticas, 2015) e pela Agenda 2030 (desenvolvimento sustentável, 2015). Nesse contexto, a edificação hospitalar se destaca por sua complexidade de funcionamento, com grande impacto no meio ambiente e no consumo de recursos. Nesse panorama, o objetivo deste artigo é apresentar e refletir sobre as inovações com sustentabilidade incorporadas no Hospital Alemão Oswaldo Cruz (HAOC), na cidade de São Paulo. Considerando esta demanda de sustentabilidade, o hospital anuncia estar comprometido com a diminuição da emissão dos gases de efeito estufa (GEE), assim como se propôs a atingir certificações importantes do mercado, como o LEED (Leadership in Energy and Environmental Design) em busca de melhores resultados de desempenho. O trabalho analisa a atuação do hospital frente ao desafio da sustentabilidade, apoiando-se em material bibliográfico sobre o meio ambiente e arquitetura sustentável contemporânea; cartilhas e relatórios publicados pelo HAOC para coleta de dados, além de fotos e registros das intervenções realizadas no hospital. $\mathrm{O}$ artigo analisa ainda, a aderência das ações do HAOC, com referência às metas do Acordo de Paris e avalia se sua contribuição com resultados favoráveis ao meio ambiente diante do cenário arquitetônico do complexo.

Palavras-chave: Arquitetura hospitalar. Hospital Alemão Oswaldo Cruz. Desenvolvimento sustentável. Certificações de sustentabilidade.

Abstract: Given the contemporary scenario, which seeks to have a careful look at the environment, São Paulo's architecture could think of changes that contribute to the goals stablished by the Paris Agreement (climate change, 2015) and the 2030 Agenda (sustainable development, 2015). In this context, the hospital building stands out for its operating complexity, with a great impact on the environment and resource consumption. The objective of this article is to present and reflect on innovations with sustainability, incorporated in the Oswaldo Cruz German Hospital (HAOC), in the city of São Paulo. Considering this demand for sustainability, the hospital announces its commitment in reducing the emission of greenhouse gases (GHG), as well as proposes into achieve important certifications in the market, such as Leadership in Energy and Environmental Design (LEED) in search for better results of performance. The work analyzes the performance of the hospital in the face of the of sustainability challenge, based on bibliographic material on the environmental and contemporary sustainable architecture; booklets and reports published by HAOC to collect data,

\footnotetext{
1 Mestre em Arquitetura e Urbanismo na Universidade São Judas Tadeu. Professora do curso de Arquitetura e Urbanismo da Universidade Paulista, E-mail: rmgomes09@hotmail.com.

${ }^{2}$ Coordenador do Programa de Pós-graduação em Arquitetura e Urbanismo da Universidade São Judas Tadeu, São Paulo. E-mail: prof.vazquez@usjt.br.
} 
photos and record the interventions performed at the hospital. The article also analyzes the adherence of HAOC's actions to in reference to the goals of the Paris Agreement and assesses whether its contribution with environment-friendly results because of the complex's architectural scenario.

Key words: Hospital architecture. German Hospital Oswaldo Cruz. Sustainable Development. Sustainability certifications.

Data de submissão: 20.10 .2020

Data de aprovação: 18.02.2021

Identificação e disponibilidade:

(https://revista.univap.br/index.php/revistaunivap/article/view/2558, http://dx.doi.org/10.18066/revistaunivap.v27i56.2558).

\section{INTRODUÇÃO}

O tema do Desenvolvimento Sustentável (DS) vem sendo discutido globalmente, desde a década de 1960, a partir da criação do Clube de Roma (1968), ainda que a popularização do tema só acontecesse no final dos anos de 1980 (PIGA; MANSANO, 2015). Nesse contexto, muitos momentos marcaram a linha cronológica da evolução dos debates, mas, é consenso que alguns foram fundamentais para o entendimento que temos hoje desta problemática, sendo eles: a Conferência de Estocolmo (1972), a publicação do Nosso Futuro Comum, pela Comissão Brundtland (1987), a Rio 92 (1992) o surgimento da ideia da existência de um "Tripé da Sustentabilidade" (preservação da natureza no âmbito social, econômico e ambiental), uma concepção original de John Elkington (2001), em meados de 1990, a Rio+20 (2012) e a 21a Conferência das Partes (COP21), que resultou no Acordo de Paris (2015). (BRASIL, 2019; LA ROVERE, 2016).

O Acordo de Paris, que foi aprovado por 195 países incluídos na ConvençãoQuadro das Nações Unidas Sobre a Mudança do Clima (UNFCCC), determinou o compromisso de diminuir a emissão de gases do efeito estufa, assim como promover a manutenção do aumento da temperatura média global em menos de 2 graus Celsius acima dos níveis pré-industriais. (LA ROVERE, 2016).

Segundo a Organização das Nações Unidas (ONU), 30\% do gás carbônico (CO2), um dos gases do efeito estufa, eliminado na atmosfera é proveniente das atividades advindas da construção civil (GOES, 2011). Dentro deste panorama, o edifício hospitalar, no seu funcionamento, é uma edificação que polui o meio ambiente. As caldeiras, ainda existentes em hospitais, produzem vapor e água quente. Além disso, ainda nos dias atuais, são utilizados os sistemas de energia. A recomendação é que se usem o gás natural, ou Gás Liquefeito de Petróleo Butano e Propano (GLP) (KARMAN, 1994). Mas, investimentos deste tipo estão longe dos projetos de remodelação ou modernização de muitos hospitais no país. Contudo, como essas adaptações seriam desejáveis, vale entender melhor os cases que já percorreram esse caminho, para visualizar possíveis soluções viáveis.

O hospital, devido a sua característica de reunir em um único complexo diversas atividades como a indústria, a hotelaria e as ações de saúde propriamente ditas, estipula a arquitetura hospitalar uma tendência intrínseca de se relacionar com práticas ecologicamente corretas como a redução da produção de resíduos, a reciclagem, o uso das águas e o uso de fontes alternativas de energia, a energia limpa 
(CARVALHO, 2006). A energia limpa, útil, advém dos recursos naturais, tais como o vento, o sol, a chuva, as marés, que, através da natureza, são renováveis e abastecidos. Ainda que muitas destas fontes energéticas estejam fora do campo restrito de muitos hospitais, a intenção subjacente nas políticas adoptadas para, pelo menos entender, a situação dramática do aquecimento global são as de causar menos problemas e diminuir um pouco mais o impacto ambiental. A energia renovável é uma parte importante e colaborativa da edificação, a nível mundial, agregada a nova tecnologia, para contribuir com a construção duradoura do futuro. (GOES, 2011; CARVALHO, 2006).

Neste estudo de caso, o hospital centenário, HAOC, foi se adequando no decorrer dos anos, desde 1890 até chegar à construção do último edifício, a torre $\mathrm{E}$, em 2012, formando um complexo de acordo com os moldes da arquitetura sustentável do século XXI, que tem a intenção de elevar as questões ambientais (HAOC, 2018).

\section{HOSPITAL ALEMÃo OSWALDO CRUZ E A SAÚDE EM SÃO PAULO}

No ano de 1897, o Hospital Alemão Oswaldo Cruz foi fundado pela Associação Hospital Alemão, por um grupo de imigrantes alemães e um Cônsul, para atendimento ao público em geral e à comunidade alemã, para oferecer um serviço de saúde que tivesse o mesmo viés cultural e de hábitos de vida que estavam acostumados (BETTIO, 2007; BERLOFI, 2014).

O hospital atuou em conjunto com as diretrizes governamentais de assistência, participando da evolução das ações de saúde pública, diante do crescimento urbano da época. Assim sendo, alguns feitos do Hospital Alemão Oswaldo Cruz e outros hospitais da cidade se direcionaram, historicamente, ao combate das doenças e epidemias que surgiram nos séculos $X I X$ e $X X$, as quais atingiam em massa a sociedade paulistana, como por exemplo: a tuberculose, a febre tifoide, a varíola, e o sarampo (HAOC, 2015).

Com a grande vinda de imigrantes no século XIX, a cidade de São Paulo, que já enfrentava problemas de insalubridade e deficiência de saneamento, aumenta ainda mais tais dificuldades e surgem as epidemias resultando, muitas vezes, em óbitos. Doenças que são transmissíveis, como a tuberculose, que matou o maior número de pessoas, seguida da febre tifoide e da varíola, espalharam-se por toda a cidade causando um grande contágio (BASSANEZI, 2014).

Estas epidemias dificultavam o desenvolvimento econômico. Por este motivo, deu-se início a reforma sanitária, surgindo o Serviço Sanitário de São Paulo (TEIXEIRA; ALMEIDA, 2003).

Foi a união de vários destes fatores, como as péssimas condições sanitárias da cidade de São Paulo, ausência das condições e hábitos de higiene, alto número de imigrantes, que ocasionaram as diversas epidemias e, dessa forma, percebeu-se a necessidade dos hospitais mais afastados, visando evitar as contaminações. Para tentar conter a disseminação destas doenças, os doentes seguiam em isolamento nos hospitais que estavam fora da zona urbana e foram tomadas também, medidas de vacinação compulsória. (ALMEIDA, 2003; OLIVEIRA, 1983).

A partir de meados do século XX, a evolução da funcionalidade hospitalar, unida aos aspectos que norteiam o Desenvolvimento Sustentável, fizeram surgir a obrigação de criar ações que aprimorassem a edificação tecnologicamente. Tais ações tinham a finalidade de que as edificações hospitalares não ficassem obsoletas, bem como promovessem a conectividade com seu usuário e apresentassem resultados mais eficazes de desempenho, tornando fundamental práticas de ações mais conscientes 
e duradouras, prevendo um futuro ecologicamente correto (ROMERO, 2011).

No século $X X I$, o cuidado na cura das doenças físicas, junta-se com a preocupação pelo estado emocional e a comodidade do indivíduo (usuário), de forma que o conceito de hospitalidade no edifício hospitalar estende-se ao acolhimento. Se, na década dos anos 1980, destacavam-se a ciência e tecnologia, no século XXI as ações internas do hospital foram ampliadas para um melhor atendimento e o bemestar do paciente, que passou a ser chamado de cliente, com a implantação da hotelaria hospitalar (BOEGER, 2011).

Conforme ressalta Boeger (2008), Gestor em Hotelaria e Facilities (mão de obra especializada):

\begin{abstract}
Uma das definições mais objetivas de Hotelaria Hospitalar é a seguinte: a Hotelaria Hospitalar é a reunião de todos os serviços de apoio, que, associados aos serviços específicos, oferecem aos clientes internos e externos conforto, segurança e bem-estar durante seu período de internação. (BOEGER, 2008, p.24).
\end{abstract}

O edifício hospitalar, focado em sustentabilidade, inclui o atendimento a fatores pouco estudados anteriormente, como: ergonomia (mais adequada aos clientes), conforto térmico dos ambientes, uso de cores adequadas para cada tipo de usuário e local do estabelecimento, paisagismo (interno e externo). Esta nova perspectiva de entendimento do edifício hospitalar, unida aos recursos humanos, passou a ser um dos fatores fundamentais na concepção, e manutenção, dos hospitais contemporâneos (BOEGER, 2011).

De acordo com Goes (2011):

O hospital é um dos programas mais complexos a ser atendido pela composição arquitetônica. É um edifício multifacetado, onde interagem relações diversas de alta tecnologia e refinados processos de atuação profissional (atendimento médico e serviços complementares) com outras de características industriais (lavanderia, serviço de nutrição, transportes, etc. (GOES, 2011, p.47).

\title{
3 A HISTÓRIA E A CONSTRUÇÃO DO HOSPITAL ALEMÃO OSWALDO CRUZ
}

A "Associação Hospital Alemão" foi fundada em 1897 pelo Cônsul Honroso da Alemanha Anton Zerrener, juntamente com a Comunidade de Imigrantes Alemães. A intenção era a construção de uma instituição de saúde para atender as pessoas da colônia alemã e a população local (BETTIO, 2007; BERLOFI, 2014).

Para a construção do Hospital Alemão Oswaldo Cruz foi comprado, em 1905, o terreno com área de $23.550 \mathrm{~m}^{2}$ perto da Avenida Paulista. Foram realizadas campanhas para se conseguir iniciar as obras do projeto do hospital, assinado pelo arquiteto alemão Curt Hildebrand. O prédio construído tem características rurais apropriadas para aquela época, possui telhado de telhas de barro, que perduram até hoje (HAOC, 2015).

O HAOC passou por várias etapas de construção, começando pelo primeiro pavilhão, que hoje é chamado de Torre $A$, até chegar à década de 1980 , na qual começaram os investimentos para a renovação e modernização do complexo hospitalar (BETTIO, 2007; HAOC, 2015). 
Figura 1 - Imagem do primeiro pavilhão, a atual Torre A, em 1923.

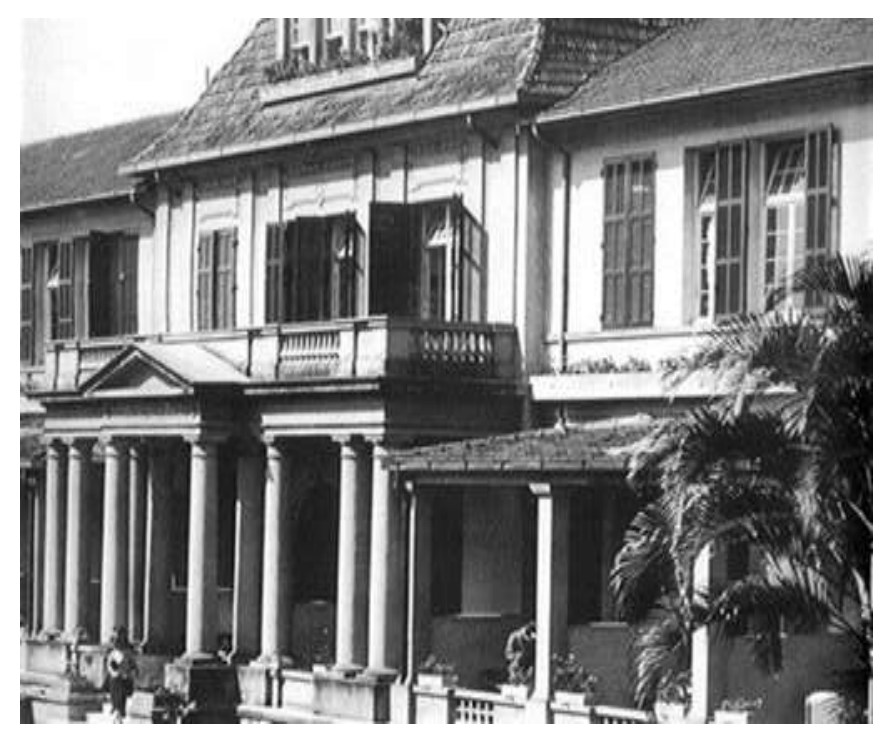

Fonte: HAOC (2017a).

O primeiro prédio teve a sua obra concluída no ano de 1923 , iniciando o funcionamento neste mesmo ano, com um total de 50 leitos. A obra deste pavilhão hospitalar contava com uma arquitetura arejada para os padrões da época, pois trazia características das casas de fazenda, com suas janelas altas, fachada avarandada e telhado de telha de barro (BETTIO, 2007; HAOC, 2017a).

Um diferencial do HAOC, destacando a área externa do hospital, em relação a outros hospitais, é o fato de poder ter aproximadamente 300 árvores e outras espécies de flores espalhadas pelos jardins. Sendo que, parte destes jardins formam o bosque "Bem-estar", uma área voltada ao lazer para pacientes, colaboradores e profissionais da área de saúde, para a prática de atividades físicas e de relaxamento, numa área de $2.000 \mathrm{~m}^{2}$ (HAOC, 2015). O antigo pavilhão de 1897 está contemplado na Resolução CONPRESP 22/2002, que trata do tombamento do Bairro da Bela Vista (SÃO PAULO, 2002).

Nos anos de 1980, avançaram em modernização de instalações de sistema de controle eletrônico e centro cirúrgico avançado. Em meados dos anos 1990, foi finalizado, na frente do prédio antigo, o hall principal da entrada e 3 andares de subsolos para o estacionamento, a torre C (HAOC, 2017b) ${ }^{3}$.

Em 1996, foi concluída a obra subterrânea do Centro de Diagnóstico por Imagem (CDI). No ano 1997, ano do centenário do Hospital, foram finalizadas as obras da Torre $C$, do novo Hall de acesso e o estacionamento subterrâneo de 3 pavimentos que fica na frente da Torre A (HAOC, 2017c).

O escritório Botti e Rubin, terminou, em 1999, o Edifício de Apoio e Serviços do HAOC e iniciou o projeto de ampliação do hospital, criando o complexo HAOC, a obra foi concluída em 2001. Os mesmos arquitetos realizaram também o Plano Diretor do Hospital. O novo edifício reservado às internações possui 18 andares e heliponto, é a Torre B, inaugurada em 2002. Possui característica contemporânea, com esquadrias em alumínio e pele de vidro, o desenho foi adequado visando respeitar uma árvore nativa centenária. A ligação do edifício ao prédio antigo foi feita por passarelas (HAOC,

\footnotetext{
${ }^{3}$ Ver também a resolução do CONPRESP sobre o bairro onde o hospital se encontra. Afinal, o antigo pavilhão de 1897 está contemplado na Resolução CONPRESP 22/2002, que trata do tombamento do Bairro da Bela Vista (SÃO PAULO, 2002).
} 
Figura 2 - Implantação do HAOC com sobreposição de desenho esquemático da autora.

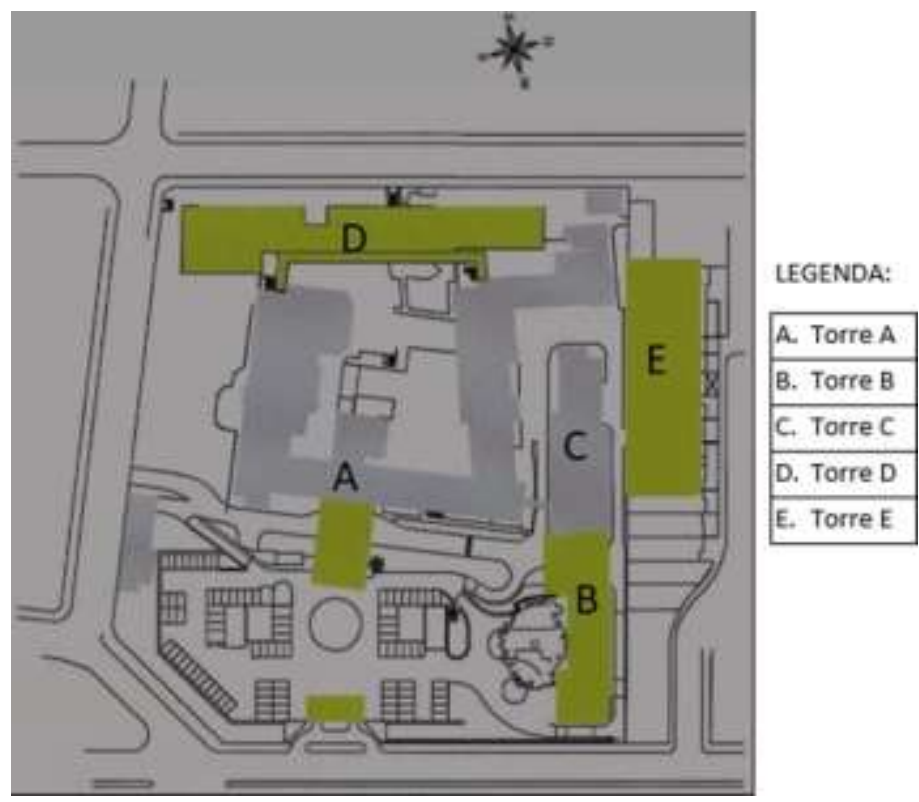

Fonte: Adaptado de Revista Projeto (2002).

Figura 3 - Fachada atual do HAOC.

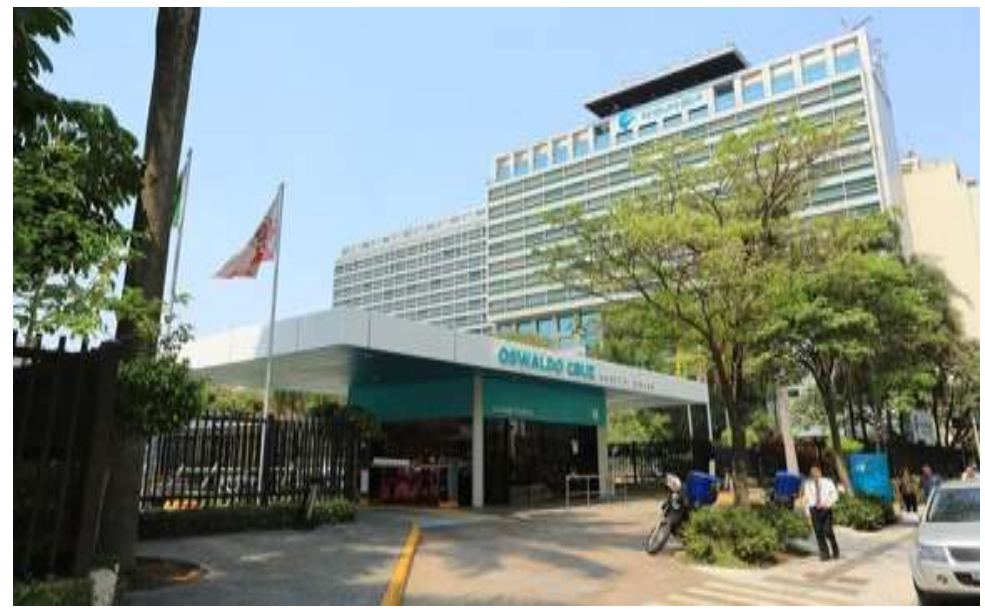

Fonte: Saúde Business (2017).

Em 2006, mais um edifício do complexo foi concluído, a Torre D, com restaurante, área de lazer com espaço verde e área de convívio para os funcionários. Um local pensado para promover o bem-estar dos colaboradores e relacionado à saúde, segurança e ao meio ambiente, temas importantes sobre ambiente saudável de trabalho que, atualmente, fazem parte dos 17 objetivos do Desenvolvimento Sustentável.

No ano de 2009 iniciou-se a Torre E, um edifício contemporâneo com amplas esquadrias em alumínio e que, em 2012, foi concluída. Inaugurada em 2013, é constituída de 25 andares, sendo distribuídos entre subsolos, internação, Unidade de Tratamento Intensivo (UTI), centro cirúrgico com alta tecnologia e auditório. Essa torre carrega o título de "edifício 
verde" exatamente por adotar a linha de crescimento sustentável desde o início da obra. O projeto desta torre teve como foco a sustentabilidade, contando com um projeto que considera a iluminação e a ventilação naturais, gerando conforto ambiental, aperfeiçoamento da gestão hídrica, no qual foi criado o sistema de reuso das águas das chuvas, que são coletadas e ficam armazenadas nos reservatórios, depois são cloradas e utilizadas nas descargas das bacias sanitárias e no sistema de ar condicionado, além de um sistema solar para o aquecimento das águas (HAOC, 2015).

Figura 4 - As 5 torres do Complexo HOAC.

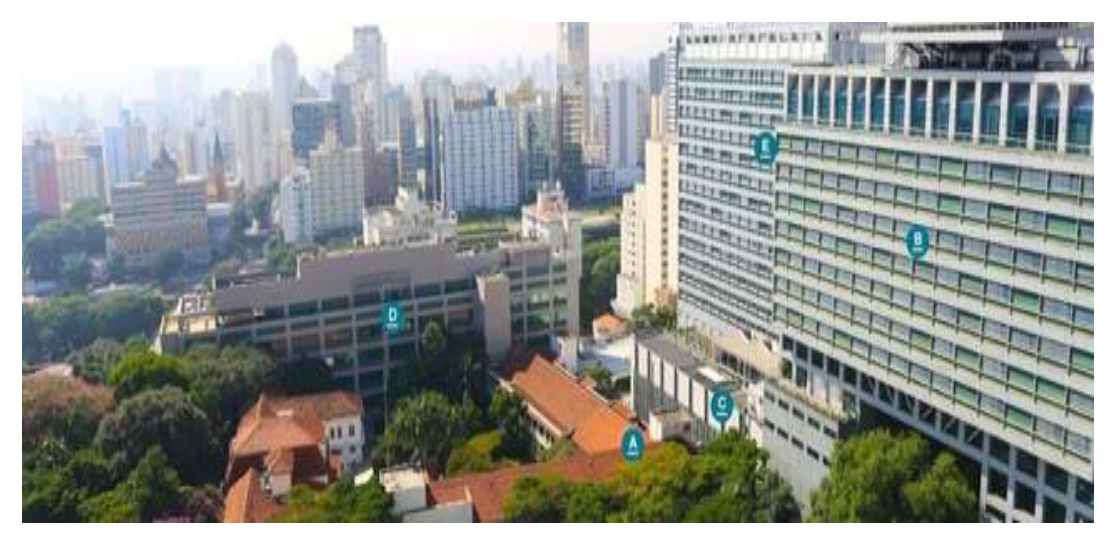

Fonte: HAOC (2019).

Além das adaptações feitas nos prédios antigos e nas novas torres construídas do complexo, o hospital conta ainda com um poço artesiano no interior da construção e uma usina de geração de energia, visando sua autossuficiência energética e um menor impacto ambiental (HAOC, 2018).

Em uma entrevista de 2013, o arquiteto Marc Rubin, relatou a importância da característica das fachadas do hospital, a fachada "caseira", como ele a chamou, em que todos os quartos possuem varandas voltadas para a orientação solar norte, o que sempre foi mais adequado para estes ambientes, fornecendo ao local mais conforto térmico e, com isto, reduzindo o consumo de energia do ar-condicionado.

O complexo do hospital tem a seguinte setorização (para melhor entendimento dos ambientes do complexo hospitalar):

\section{TORRE A}

- Centro de Diagnóstico por Imagem - Centro Especializado em Oncologia • Centro Especializado em Ortopedia - Pronto Atendimento Ortopédico - Nefrologia e Diálise • Ambulatório de Especialidades • Neurofisiologia Clínica • Centro Especializado em Tumores do Cérebro e Coluna • Centro Especializado em Hérnia • Cardiologia • Clínica Médica.

\section{TORRE B}

- Centro Cirúrgico • Centro de Intervenção Cardiovascular, Unidades de Internação, Cardiologia não invasiva, Day Clinic, Endoscopia e Colonoscopia • Centro de especialidades e check-up.

\section{TORRE C}

- Pronto Atendimento.

\section{TORRE D}


- Instituto de Educação e Ciências em Saúde (IECS) • Faculdade de Educação em Ciências da Saúde (FECS) • Escola Técnica de Educação em Saúde (ETES); Centro Especializado em Urologia • Centro Especializado em Cirurgia Robótica; Centro de Atenção à Saúde e Segurança do Colaborador (CASSC) • Unidade de Onco-hematologia, restaurante, Academia e Área de lazer e convivência.

\section{TORRE E}

- Internação • Centro Cirúrgico • UTI • Apartamentos do serviço Premium.

O complexo do Hospital Alemão Oswaldo Cruz (Unidade Paulista) tem $96 \mathrm{mil} \mathrm{m}^{2}$ de área construída, conta com 306 leitos de internação, mais 44 leitos de UTI e 22 salas para cirurgias.

Figura 5 - Visão panorâmica do complexo do HAOC.

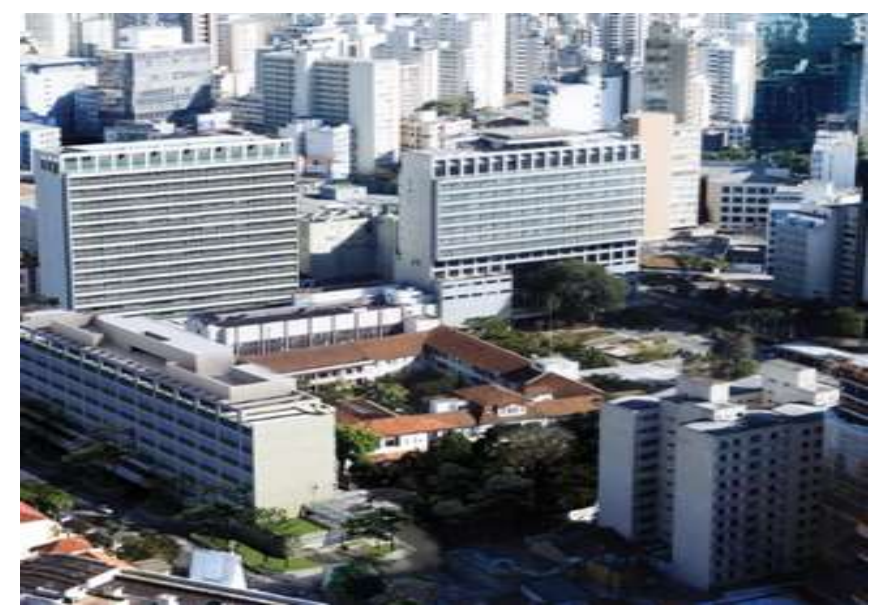

Fonte: MHA Engenharia (2020).

Figura 6 - Torre E vista do pátio interno HAOC.

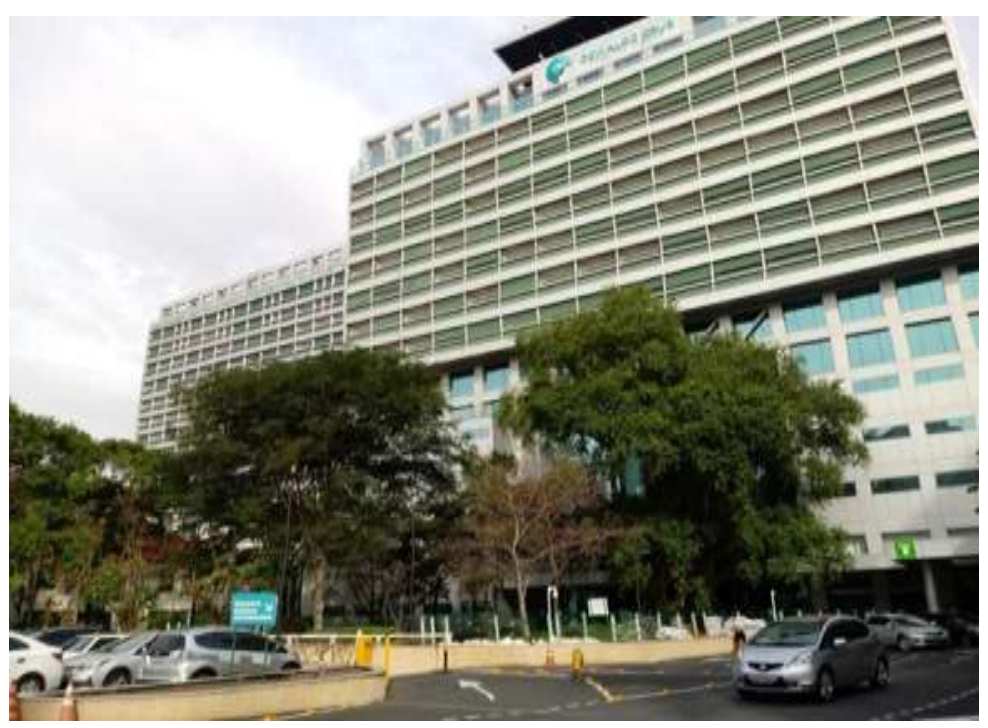

Fonte: Acervo da autora, 2019. 
Figura 7 - Torre E vista do pátio interno HAOC.

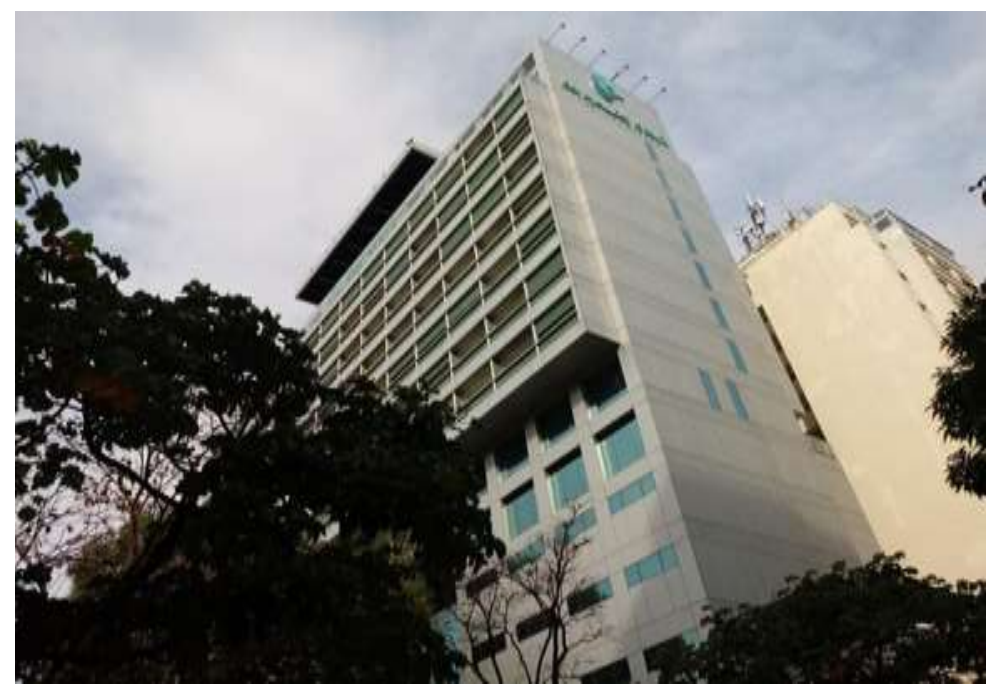

Fonte: Acervo da autora, 2019.

\subsection{CERTIFICAÇÕES E ACREDITAÇÕES DO HOSPITAL ALEMÃO OSWALDO CRUZ}

No século XXI, o HAOC, introduzido no ramo de negócios voltados para a área hospitalar, com impactos próprios, que vão da aproximação aos serviços de saúde ao alto consumo de recursos naturais, tentou um ajuste, criando uma agenda de temas sustentáveis no hospital, a partir da integração de métodos e aspectos ambientais e sociais (HAOC, 2015).

Em 2009, o HAOC recebeu a certificação Joint Commission International (JCl) e, em 2019, novamente e pela quarta vez, recebeu a mesma certificação $(\mathrm{JCl})$. A Joint Commission International é um organismo não governamental de acreditação de instituições ligadas à saúde, que visa aprimorar a segurança e qualidade dos cuidados com os pacientes, avaliando todos os serviços prestados e as instalações do edifício hospitalar (HAOC, 2018; JOINT COMMISSION INTERNATIONAL, 2014).

O HAOC, em 2015, sustentou as ações de controle dos impactos ambientais, com base na ecoeficiência e em pontos importantes como os resíduos, o uso da água e a energia (HAOC, 2015).

A Torre E foi construída de acordo com alguns diferenciais de eco eficiência, como: o sistema solar para o aquecimento de água; o uso das águas das chuvas; uso de minas localizadas no subsolo para utilização das descargas dos sanitários e dos jardins; projeto arquitetônico voltado para abrangente captação de luz solar, para menor consumo de energia e eficiente sistema de climatização com os quartos avarandados e voltados para os jardins; além das vagas especiais para veículos de baixa emissão e baixo consumo (como híbridos) e bicicletário para incentivar toda a prática de exercícios físicos, os quais diminuem riscos de doenças cardiovasculares e, também, causam uma melhoria no fluxo do trânsito da região, além de contribuir com benefícios para as pessoas, com a redução na emissão de $\mathrm{CO}^{2}$ (HAOC, 2015).

A obtenção da certificação LEED vinculou-se ao registro do projeto junto ao Green Building Council (GBC), seguido de uma minuciosa auditoria para confirmar a execução dos itens previstos em projeto, seguindo as diretrizes preconizadas pelo manual LEED (HAOC, 2015). 
No ano de 2015, a Torre E do HAOC recebeu a importante certificação LEED GOLD de construção sustentável com acreditação ambiental para edificações. $O$ HAOC conquistou a certificação "Leadership in Energy and Environmental Design" (LEED) nível Gold (ouro) na categoria NC (Novas Construções) (HAOC, 2015).

A certificação LEED precisa de 40 a 49 pontos (LEED Certificado), de 50 a 59 pontos (LEED Prata), a pontuação de 60 a 79 (LEED Ouro) e pontuação maior que 80 (LEED Platina), que serão somados por meio de uma combinação de créditos e pode atingir até 110 pontos para medição de desempenho das categorias de sustentabilidade (GBC Brasil, 2019).

O LEED é um certificado chancelado pela organização Green Building Council (GBC), que segue o formato do United States Green Building Council (USGBC), fundado em 1993. O Green Building Council (GBC) certifica as edificações com potencial sustentável, quando comprovados os atendimentos a uma série de prérequisitos e critérios estipulados pela organização. Conforme o edifício cumpre com os critérios, ele recebe pontos, que no final, somados, classificam o nível de certificação (GBC Brasil, 2019).

Figura 8 - Pontuação e níveis de Certificação LEED.

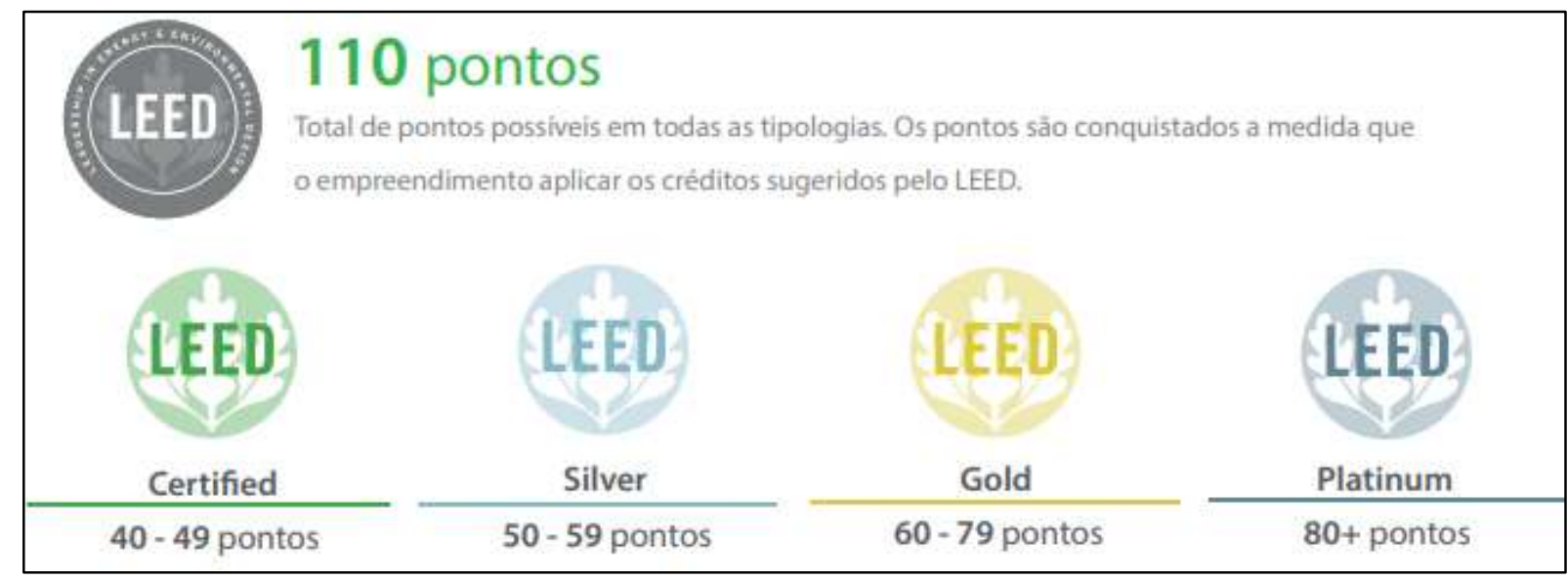

Fonte: GBC Brasil (2019).

O Hospital Oswaldo Cruz obteve 63 pontos atingindo a pontuação necessária entre 60 e 79 pontos, que está dividida em 7 categorias, a qual the rendeu a certificação nível ouro (LEED GOLD) LEED BD + C: Nova Construção v3 - LEED 2009. 
A eficácia nas instalações também faz parte dos fatores fundamentais para um hospital saudável.

\section{CONCLUSÃO}

Mesmo sabendo que não é fácil propor conclusões em um estudo de caso, por se tratar de um exemplo representativo (um hospital referência na cidade de São Paulo), a análise apresentada demonstra que o Complexo do HAOC, busca tratar a arquitetura do edifício em comunhão com as metas do Acordo de Paris, comprometendo-se em diminuir a emissão dos gases de efeito estufa (GEE) e, buscando proteger o meio ambiente, procurando por bons resultados de desempenho, o que é de fundamental importância para reduzir o impacto ambiental de construções desta complexidade no futuro. Apresentando, um caminho possível a ser seguido por outros equipamentos do mesmo tipo.

A sustentabilidade aplicada na arquitetura hospitalar do HAOC mantém um olhar voltado para a redução de consumo de energia e de água, que são elementos de atenção nos relatórios anuais do hospital relacionados às questões ambientais, com a obtenção de eco eficiência do sistema solar para o aquecimento de água e gerador de energia limpa, a criação do sistema de reuso das águas das chuvas, que são coletadas, tratadas e reservadas para usos diversos. O último edifício do complexo hospitalar teve o título de "edifício verde", porque adotou, desde o início da construção, uma linha de evolução sustentável, com ambientes projetados para uma boa iluminação e ventilação naturais, propiciando conforto ambiental adequado, em ambientes que podem ficar abertos, sem o uso constante ar-condicionado, voltado para um belo jardim com várias espécies centenárias. Todas estas características, somadas às ações que envolvem o conceito de hospitalidade, proporcionando acolhimento e humanização, tornam o hospital um ambiente de sustentabilidade duradouro.

O HAOC possui certificações necessárias para poder ser considerado um edifício saudável e sustentável, conforme resultou no recebimento do LEED GOLD no ano de 2015 , demonstrando a possibilidade de um estabelecimento de saúde, mesmo sendo um edifício considerado poluente pela sua complexidade, conseguir reduzir seus impactos ambientais. Nesse contexto, o hospital criou ações voltadas para uma conscientização de responsabilidade social e sustentável, conforme informações adquiridas junto ao estudo de caso. No HAOC fica evidente, pelos resultados obtidos, que é o caminho mais adequado, tanto do ponto de vista empresarial (pela evidente redução de custos e o aumento no bom relacionamento com os pacientes, funcionários parceiros e fornecedores), como do ponto de vista global (com uma adequada resposta à problemática do aquecimento global, o favorecimento pelas fontes de energia renováveis e, sobretudo, pela adequação aos enunciados do "Tripé da sustentabilidade"). Parece bastante factível pensar que é um caminho possível, e, que poderá ser trilhado por outras instituições hospitalares de São Paulo.

\section{REFERÊNCIAS}

ALMEIDA, M. República dos invisíveis: Emílio Ribas, microbiologia e Saúde Pública em São Paulo (1898-1917). Bragança Paulista: Edusp; 2003. 
BASSANEZI, M. S. C. B. Imigração e mortalidade na terra da garoa. São Paulo, final do século XIX e primeiras décadas do século XX. In: ENCONTRO NACIONAL DE ESTUDOS POPULACIONAIS, 19., 2014, São Pedro, SP. Anais [...]. Rio de Janeiro: Associação Brasileira de Estudos Populacionais, 2014. p. 1-18. Disponível em: http://www.abep.org.br/publicacoes/index.php/anais/issue/view/38. Acesso em: 29 set. 2020.

BERLOFI, L. M. Caracterização e organização da força de trabalho de enfermagem do hospital alemão Oswaldo Cruz no contexto da segunda guerra mundial. 2014. 135 f. Dissertação (Mestrado) - Escola Paulista de Enfermagem, Universidade Federal de São Paulo (UNIFESP), São Paulo, 2014.

BETTIO, M. Análise do impacto da acreditação hospitalar no processo de planejamento e qualidade na gestão do Hospital Alemão Oswaldo Cruz. 2007. 91 f. Trabalho de Conclusão (Bacharel em Administração) - Departamento de Ciências da Administração, Universidade Federal de Santa Catarina, Florianópolis, 2007.

BOEGER, M. A. Gestão em hotelaria hospitalar. São Paulo: Atlas, 2008.

BOEGER, M. Hotelaria Hospitalar. São Paulo: Manole, 2011.

BRASIL. Ministério do Meio Ambiente. Acordo de Paris. 2019. Disponível em: http://www.mma.gov.br/clima/convencao-das-nacoes-unidas/acordo-de-paris. Acesso em: 12 out. 2019.

CARVALHO, A. P. A. Quem tem medo da arquitetura hospitalar? Salvador: Quarteto; FAUFBA, 2006.

ELKINGTON, J. Canibais com garfo e faca. Tradução ao português de Patrícia Martins Ramalho. São Paulo: Makron Books, 2001.

GBC BRASIL. Compreenda o Leed. São Paulo: Green Building Council, 2019. Disponível em: <https://www.gbcbrasil.org.br/docs/leed.pdf> Acesso em: 23 set 2019.

GOES, R. Manual Prático de Arquitetura Hospitalar. 2. Ed. São Paulo: Edgard Blucher, 2011.

HAOC. Hospital Alemão Oswaldo Cruz. Complexo Hospitalar, 2019. Disponível em: https://www.hospitaloswaldocruz.org.br/o-hospital/complexo-hospitalar. Acesso em: 01 mar. 2020.

HAOC. Hospital Alemão Oswaldo Cruz. Relatório de sustentabilidade, 2018. Disponível em: https://relatoweb.com.br/haoc/2018/190925a/pdf/HA OswaldoCruz 2018 PT.pdf. Acesso em: 17 dez. 2019.

HAOC. Hospital Alemão Oswaldo Cruz. Relatório de sustentabilidade, 2015. Disponível em: https://www.hospitaloswaldocruz.org.br/wp- 
content/uploads/2017/02/HAOC-Relatorio-Anual-2015.pdf. Acesso em: 05 mar. 2019.

HAOC. Hospital Alemão Oswaldo Cruz. Relatório do HAOC, 2017a. Disponível em: https://www.hospitaloswaldocruz.org.br/o-hospital/historia.pdf. Acesso em: 22 set. 2020.

HAOC. Hospital Alemão Oswaldo Cruz. Releases, 2017b. Como consta nos registros Disponível em:

https://www.hospitaloswaldocruz.org.br/imprensa/releases/185-anos-de-imigracaoalema-no-brasil-o-hospital-alemao-oswaldo-cruz-faz-parte-dessa-historia.pdf. Acesso em: 21 set 2020.

HAOC. Hospital Alemão Oswaldo Cruz. Sobre-nós, 2017c. Disponível na história do hospital em: https://www.hospitaloswaldocruz.org.br/sobre-nos.pdf. Acesso em: 21 set 2020.

JOINT COMMISSION INTERNATIONAL (JCI). 2014. Disponível em: https://www.jcrinc.com/-/media/deprecated-unorganized/imported-assets/jcr/defaultfolders/items/ebjcih14b sample pagespdf.pdf?db=web\&hash=22513968F3BD3D76 53E69A96EFAC5\%20234.pdf. Acesso em: 22 set. 2020.

KARMAN, J. Manutenção Hospitalar Preditiva. São Paulo: Pini, 1994.

LA ROVERE, E. L. O Brasil e a COP-21. Rio de Janeiro: Die, 2016. v. 1. Disponível em: http://www.centroclima.coppe.ufrj.br/images/O Brasil e a COP-21 -

Emilio La Rovere.pdf. Acesso em: 17 maio 2019.

MHA Engenharia. Hospital Alemão Oswaldo Cruz, 2020. Disponível em: https://w3.mha.com.br/wp/portfolio/hospital-alemao-oswaldo-cruz-5/>. Acesso em: 01 mar. 2020.

OLIVEIRA J. L. Contribuição para a história da Saúde Pública paulista. 1986. Dissertação (Mestrado em Saúde Pública) Pontifícia Universidade Católica de São Paulo, São Paulo, 1986.

PIGA, T. R.; MANSANO, S. R. V. Sustentabilidade ambiental e história: uma análise crítica. Perspectivas contemporâneas, v. 10, n. 2, p. 174-195, 2015.

PROJETO. Botti Rubin Arquitetos Associados: Hospital Alemão Oswaldo Cruz, São Paulo. Projeto (online), São Paulo, 29 dez. 2002. Disponível em: $<$ https://revistaprojeto.com.br/acervo/botti-rubin-arquitetos-associados-hospitalalemao-29-11-2002/>. Acesso em: 01 mar. 2020.

ROMERO, Marta Adriana Bustos (org.). Tecnologia e sustentabilidade para a humanização dos edifícios de saúde: registro do curso de capacitação em arquitetura e engenharia, aplicado à área da saúde, hemoterapia e hematologia. Brasília: Faculdade de Arquitetura e Urbanismo, Universidade de Brasília, 2011.

SÃO PAULO (Cidade). Resolução Secretaria Municipal de Cultura SMC/CONPRESP $\mathrm{n}^{\circ} 22$ de 13 de dezembro de 2002. Diário Oficial da Cidade, São 
Paulo, p. 10, 14 dez. 2002. Disponível em:

http://legislacao.prefeitura.sp.gov.br/leis/resolucao-conselho-municipal-depreservacao-do-patrimonio-historico-cultural-e-ambiental-da-cidade-de-sao-pauloconpresp-22-de-13-de-dezembro-de-2002//detalhe. Acesso em: mai. 2020.

SAÚDE BUSINESS. Hospital Alemão Oswaldo Cruz anuncia nova marca, 2017. Disponível em: https://saudebusiness.com/mercado/hospital-alemao-oswaldo-cruzanuncia-nova-marca/. Acesso em: 01 mar. 2020.

TEIXEIRA, L. A.; ALMEIDA, M. Os primórdios da vacina antivariólica em São Paulo: uma história pouco conhecida. História, Ciências, saúde, Manguinhos, v. 10, Supl. 2, p. 475-98, 2003. Doi: https://doi.org/10.1590/S0104-59702003000500003. 